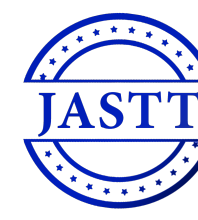

\title{
Energy Management for Internet of Things via Distributed Systems
}

\author{
Mohammed A. M.Sadeeq ${ }^{1}$, Subhi R. M. Zeebaree ${ }^{2}$ \\ ID Duhok Polytechnic University,Duhok,Iraq,mohammed.abdulrazaq@dpu.edu.krd \\ ${ }^{2}$ Duhok Polytechnic University, Duhok, Iraq, subhi.rafeeq@dpu.edu.krd
}

\begin{abstract}
The distributed energy system (DES) architecture is subject to confusion about renewable energy limits, primary energy supply and energy carriers' costs. For the grid to use unreliable electricity sources, the end-user's on-demand presence in the intelligent energy management context is essential. The participation of end-users could influence the management of the system and the volatility of energy prices. By delivering auxiliary services using demand side-resource to increase system reliability, robust planning, constraint control and scheduling, consumers may support grid operators. The optimized approach to managing energy resources enhances demand response to renewable energy sources integrally, controls the demand curve with load versatility as the system requires it. The opportunity to adjust/regulate the charging profile by choosing a particular device. This article discusses a literature and policy analysis that looks at the role of energy management system aggregators and the end-users participating in subsidiary systems within Smart Grid programmers and technologies. In the implementation of aggregators for energy management systems, the objective is to understand the patterns, threats, obstacles and potential obstacles.
\end{abstract}

Keywords: Energy Management, Energy Consumption, Energy Transformation, IoT, Distributed Systems.

Received: February 9, 2021 / Accepted: April 14, 2021 / Online: April 17, 2021

\section{INTRODUCTION}

In the past few years, (IoT) in towns, buildings, universities, warehouses, businesses, poultry, hospitals, and health centers have penetrated most human living areas. [1,2]. The network of (IoT) physical devices, vehicles, home equipment, and other components are embedded into electronics, software, sensors, drives, and communication networks that allow these objects to collect and exchange data $[3,4]$. Everything can be identified uniquely by its incorporated machine but interact with the existing internet infrastructure [5]. The IoT enables objects to be detected or operated directly via existing network technology, enabling a closer connection between the real world and computer-based networks and enhancing performance $[6,7]$.

IoT is applicable in a large field of science and technology [8]. They are used in computing, big data, smart cities, mobile charging networks, smart monitoring, smart power systems, water supply, environmental security, smart retail, smart supply chain, online shopping [9-11]. The new IoT concept provides an open door for creative applications that organize the renowned conventional computer advances. IoT attempts to communicate with these self-governing gadgets in order to create related information without human mediation. The IoT happens when every day, recognizable objects are linked to microchips $[12,13]$.

In the last 5-10 years, IoT platforms and services have changed with open-source hardware availability. The progress of this new technology is expected to begin. Students would have to be taught IoT principles and best accessible technologies, which freely incorporate new technology into their work later on [14]. The LoRa WAN Standards-dependent middleware is a core component of this IoT scheme [15]. The technology of Lora is used to link sensors beyond the internet spectrum to access points. The software is then chosen as opposed to the hardware used. Moreover, data vary from system to system, so a "data repository" is necessary if posted earlier rather than later for reliability [16-18]. 
Energy efficiency delivers long-term economic gains by decreasing import/supply costs for fuel, generating energy, and reducing renewable emissions. Effective monitoring of realtime power supply chain data plays an important role in increasing demand generation. Optimizing energy storage includes three primary parts: (I) energy sources that include upstream refining processes; (II) energy transfer processes involve energy storage and distribution systems; and (III) energy demand within buildings and transport sector. energy supply chains; distribution. [19, 20]. IoT uses sensors and networking systems to detect and transfer real-time information in fast computing and effective decision-making. IoT will also turn the energy sector into a centralized, smart, and optimized electricity grid. Automatic, integrate, and monitor processes through IoT-based systems via communication technologies and sensors [21]. Comprehensive data analysis and sophisticated algorithms can help consumers and applications track energy use trends and handle consumption better in various time frames. [22-24].

The energy usage market incorporates a range of innovative monitoring responses, including the Epi-Sensors, Wi-Lem, Wattsup, SATEC, Change Electric, Energy Metering Advancement LTD, General Power, Mitsubishi, Siemens, and Schneider. Thus, many businesses supply emergency energy management (EEM) software systems to break down collected data, such as Resource Kraft, Google, e-view, and EFT Energy. By summarizing provisionally accepted procedures, which will specify a general energy monitoring system using advancements in Internet technologies, a wired or wireless system may be credited. Several parameters can be accomplished to measure and estimate energy usage, suggesting harsh energy conditions of energy shortage (e.g., energy consumption, power factor, maximum and minimum voltage) [25-27].

This article covers IoT technologies from electricity generation to Transmission and Distribution (T\&D) and development on the energy market. This paper's critical contribution is to widen current literature by exploring the possibilities and challenges of applying IoT to energy regulators, researchers, energy specialists, and energy managers around the energy market. For example, in intelligent buildings, IoT functions are addressed without concentrating on typologies, building materials, resident energy use behaviors, shape, and domestic equipment.

The rest of this work is organized as the following background theory in section two. In section three, the energy management Survey. All mentioned and reviewed researches are compared and discussed in section four. Finally, in section five, the conclusion of this work is presented.

\section{BACKGROUND THEORY}

\section{A. IoT Applications}

IoT technology uses are different because they can be applied to almost any technology and can provide knowledge about the intervention process, operation performance, and the environmental variables that must be controlled and monitored from a distance[28]. Today, several organizations in different sectors and industries use this technology to minimize, create, automate, and track several processes [29]. The figure below shows some IoT use in different sectors [30].

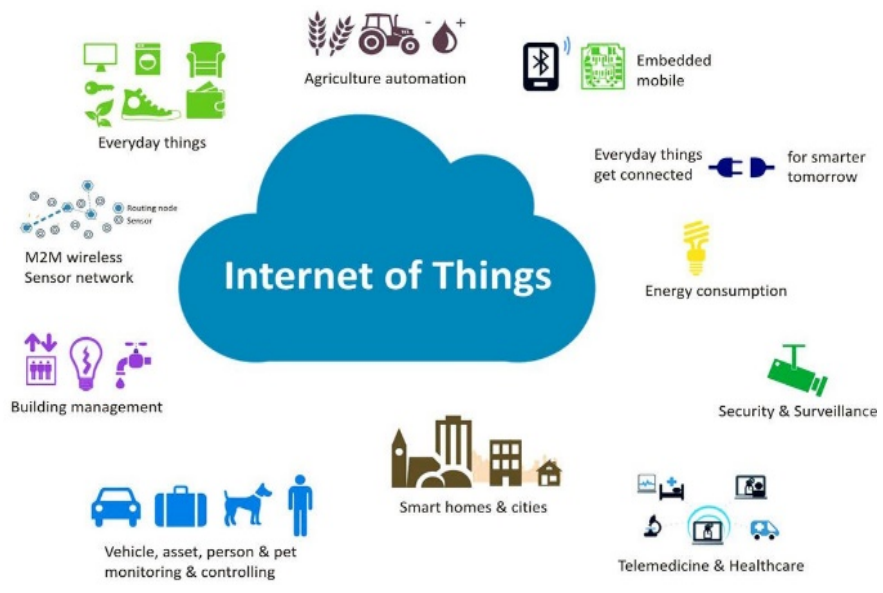

Fig. 1. Internet of Things Applications [30]

\section{B. The architectural design of IoT}

An open architecture that uses open protocols to support many existing network applications to provide scalability, security, and semantic middleware to facilitate worldwide Internet data convergence should provide an IoT architecture. IoT should then be a five-layer system as shown in fig 2 [31-33]: Sensing and control layer: the basis for the design and deployment, including RFID readers, smart sensor nodes, and entry gateways [34]. A group of sensor nodes sensor the associated ambient information, pass it to the nearest gateway and then transmit data from the internet to the network. The energy supply system consists of three primary parts: the energy sources included in upstream refining processes, (II) energy transfer processes, and (III) the energy demand within buildings and transport. Energy supply chains; distribution. Processing layer: Reasoning, semantic analysis of sensing data, data query, data collection, analytical data, mining. Cloud computing could provide a powerful tool for data processing and sensing. It is an integral part of the knowledge set. Application layer: The application layer uses this data to provide users with various services after data collection and analysis. The IoT software can be classified, Into network monitoring (logistics, regulation of emissions), control form (smart transport, intelligent home), scanning type (motor bag, highway, no parking costs).

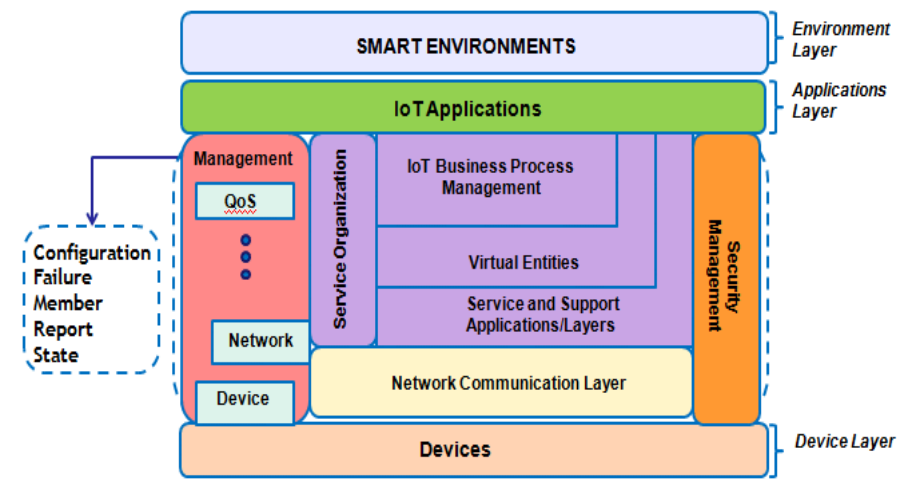

Fig. 2. Internet of Things Architecture [31-33] 


\section{Resources and IoT}

Automation of industrial processes, data acquisition, and control systems have been standard in the power industry. The early steps of IoT started by monitoring and controlling installations and procedures to minimize the risk of a power supply breakdown or failure. Sustainability, performance, environmental impacts, and maintenance are critical problems for old power plants. The age and general maintenance problems of the electrical equipment contribute to high energy losses and unreliability. Suppose we use our IoT sensors to calculate power plant efficiencies. In that case, the data transmitted will allow us to understand how the systems are working by detecting errors or declines in energy performance $[35,36]$. The compatibility of intermittent renewable energy sources such as wind and solar helps reduce the impacts of coal energy consumption [19].

\section{Consumption of electricity}

Previous studies found that renewable energy production and use significantly contribute to countries' economic and environmental activities. Green Energy's importance lies in its ecologically favourable nature and is considered a more productive natural resource for healthy commercial, human and ecological development. With countries strongly inclined to conserve the environment, environmental policy needs to explore the causal connection between clean energy and economic development. The long-term link between sustainable energy usage and economic growth has been researched. in previous studies. Therefore, the causal relationship between renewable energy and environmental destruction is essential in countries that spend tremendous capital on renewing renewables for better economic and environmental conditions [37].

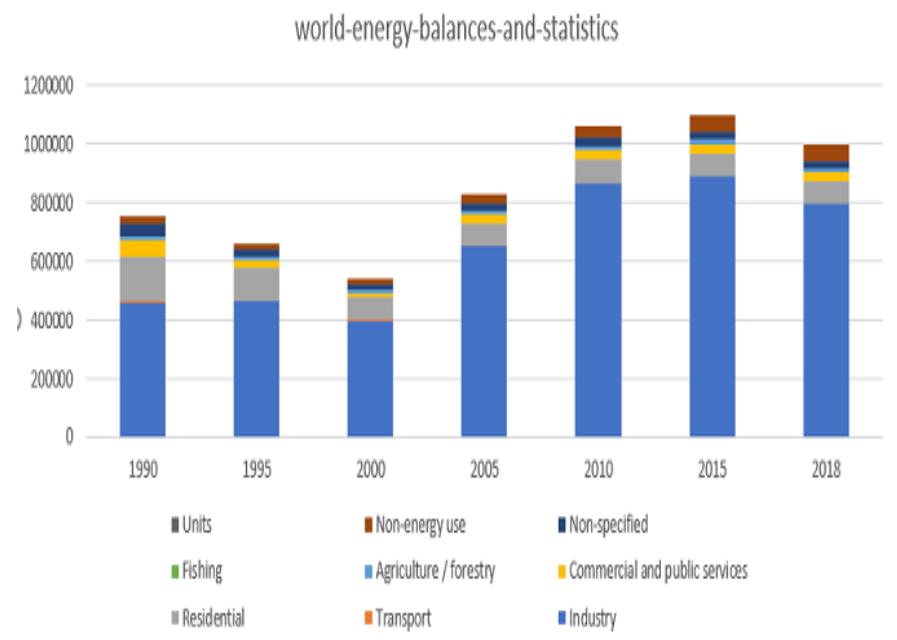

Fig. 3. Final Electricity consumption, World 1990-2018 [38]

\section{E. Green IoT}

Energy utilization of IoT equipment is a big concern, unbelievably, shortly in the wide-scale use of these technologies has been expected. Millions of wired networks are in operation; for the internet, a great deal of energy is needed. The vast number of IoT equipment will also produce a great deal of electronic waste. Low carbon and efficient communication networks are needed. These factors luckily led to the emergence of (G-IoT). G-energy compelling IoT features are essential components in the lifecycle, including design, development, implementation, and ultimate disposal. In different IoT technology, the G-IoT cycle can be used, like RFID tags. The sensor nodes can also be used in wireless sensor networks in sleeping mode and can only run when necessary. Methods for radio optimization can reduce node uses, such as modulation optimization or mutual collaboration. Besides, practical, energyefficient routing technologies may provide efficient solutions such as multi-track routing or cluster architectures. Finally, the above methods and examples Reduce energy consumption for the IoT $[19,39,40]$.

\section{F. Smart Cities}

Today, the vast population increase and overcrowding have created many global challenges, including air and water, access to power, and the atmosphere. One of the big problems is to provide safe, sustainable, and secure energy sources for communities. Recent advances in emerging technology have contributed to mobile, IoT-based applications to current challenges in a smart city climate. Smart factories, smart houses, power plants, and farms can be linked in a city, and data on their energy usage can be obtained at various hours a day [41]. In multiple processes, smart cities, transmitting and connectivity of information, intelligent recognition, deciding the location, mapping, security, emission control, and identity protection will be handled using IoT technologies [42]. IoT technology can assist in the tracking of any object in a region. Sensors may be linked to homes, urban infrastructure, transport, electricity networks, and services. This will support a smart city based on continuous monitoring of data acquired from sensors. For example, street lights can be regulated for saving energy by tracking vehicles with IoT. [43].

\section{G. Intelligent Grid}

Modern grids that use the safest and most efficient ICT to track and optimize energy production, T\&D, and use [44]. A smart grid creates a cross-directional data flow for optimum system monitoring and efficient energy supply by linking multiple smart meters. In different sub-sectors of the energy system, such as energy storage, home, transport, or careful consideration, the intelligent grid operation should be emphasized separately. Batteries are recharged in conventional grids, adapters and power cables, and AC/DC inverters. These batteries can be wirelessly charged in an intelligent grid via inductive charging technology [43]. In an intelligent grid, end users can determine the latest demand pattern by collecting data, such as phones or electric cars, via an IoT network. The nearest wireless battery charging station then assigns the necessary charging time for the device/car. IoT can also improve battery management and monitoring. So the electricity supply can be changed first and secondly the power supply for These vehicles are excellent and reliable. [45]. It will significantly minimize unnecessary waste demand. Besides that, IoT may be applied in individual islands or entities in different or microgrids, particularly where energy is required at any time, without exception in databases. Both grid-related properties connect in these networks. Energy demand data are also available for any commodity. This relationship means that every time and anywhere, the energy flow is fully regulated [46]. 


\section{H. Distributed Systems and Cloud computing}

Distributed structures should be flexible, involving topography, organization or scale $[47,48]$. The distributed system may face some problems and challenges because of the protection, which is a big concern for the system [49, 50]. When an unstable asset supplies a distributed system, fault tolerance is another issue in the distributed model [50]. Without due processes and procedures, the incorporation and deployment of services become a problem [51]. Providing processing power over a network (internet) is advantageous for cloud computing [52-54]. For clients to transact business, they do not need the services of massive, complex computers; rather, they may access cloud storage services depending upon their needs [55] [56]. The basic equipment is routinely facilitated in vastly distributed systems using various virtualization practices to achieve high scalability, availability, and agility [57]. However, cloud computing services' allocation serves as a study subject that led to groundbreaking algorithms and methods [58]. Cloud computing is the field of highest interest for telecommunications professionals, with potential uses in mind [59]. The resource-assigning technique is important to consider mind-boggling communications among persons interested in using the ready-programs [60]. Conveyed in the various server [61]. The key principles for running the ready programs inside the system are the tools required for computations [62]. The client interpreted the operation, and this way prepared them to execute it [63]. When a client provides the customer with a service, it is an activity that leads to the development of a procedure [64]. This sets the customer up to perform their operations correctly. The CPU uses this resource to access the computer's memory [65].

\section{Energy Management SurVey}

Many scholars have discussed Energy Management and its implementation frameworks in the last few years. In this section, the critical points of some of the latest research are discussed.

Shen, Ruyin Zhang, et al., [20] Considered both IoT and edge server systems. The edge server contains code blocks for the IoT platform and alleviates its minimal memory power by loading the IoT device blocks. Moreover, the IoT system can extract electricity from environmental sources in order to accomplish a sustainable process. One solution to the complex electrical issues suggested by the author is a block prefetching framework (BPF) to optimize user-friendly delays. The coalition supports the intelligent pre-historically cloud intelligent telecommunications infrastructure systems. The BPF contains a prediction module, a pre-precipitation module, and a dual learning module. The module requests blocks from the edge server depending on available memory and energy. The dual learning module tries to make the shift happen much faster. The simulations are performed to test the ability of the proposed system.

Garg, Ritu Garg, Neha[27] suggested a scheduling algorithm to equilibrium the energy produced by SEH and the IoT node energy consumption by the IoT node resulting in the balanced method. The proposed SWEH device's performance is superior to that of a single solar panel or wind turbine. These results show that the algorithm should leave the device in an energy-neutral state at the end of a particular period.

Krishnamoorthy et al. [66] Proposed an IoT method that tracks load power usage and effectively saved electricity. IoT could be used for various purposes, from home automation to sectors where real things are connected to a network from everywhere. The proposed project implements the Internet of Things (IoT) based energy management system, whereby information is obtained from an IoT automated meter and displayed on an IT website. This device can be used to measure the environmental load data and store it in the IoT network.

Bedi, Guneet, et al., [67] Created Elman's recurring neural network model and an exponential electrical power prediction model in a building environment powered by IoT. The models forecast the usage of electrical energy by an electrical load (1) in which a relationship occurs between the net consumption of energy by the electrical loads in the building and the atmospheric temperature and the building's occupancy; and (2) in which electrical energy consumption is predicted using the forecast temperature and schedule. The construction area under consideration is the Real-Time Power and Intelligent Systems Laboratory (RTPIS) combined with IoT devices and technology for intelligent monitoring and control. Heating, ventilation, and air conditioning (HVAC) units and light panels are considered electric loads. Comparisons are also rendered for the Elman RNN and exponential models. These forecast capabilities help address electricity consumption variabilities by delivering electricity to meet electricity demands, reducing electricity loss, decreased carbon emissions, and cost savings.

Lasso-Lopez et al. [68] Presented the development and deployment of an IoT prototype for energy monitoring, established by a group of undergraduates studying the challengebased learning paradigm to strengthen their disciplinary and interdisciplinary competence. This instructional approach helps students address a relevant challenge by applying new technologies and effective methodologies. The users tested the built prototype for six months. The findings demonstrate that by recognizing energy efficiency problems in the laboratories, the prototype has brought advantages relative to the students who used the conventional learning model even from a theoretical perspective.

Almonacid-Olleros, et al., [69] There have been multiple machine learning models tested to determine a photovoltaic (PV) system's behaviour and energy efficiency. The author also utilized several types of estimates for power to test computational models of solar panel systems. This is operated data from a photovoltaic device installed to monitor the energy utilization (Spain). Computer models may be more effective than analytical ones because learning time can vary, and it can be faster. Temporary windows are an effective method to quantify time variation characteristics to enhance performance.

Avancini, Danielly BRodrigues, et al., [70] Built and actual verified a low-cost smart meter solution for internet-based energy monitoring. It forwards the data collected by smartphones via Wi-Fi and collects them using an IoT middleware equipped with energy-management ability. The intelligent meter is automatically regulated as well as 
electronically collected. To that end, Bluetooth, ZigBee, and 6LowPAN protocols (or 6LoWPAN RF4CE) will be enabled. The Wi-Fi was used to understand the smart meter and the IoT's communication capability, then verify this. It can be automated in an intelligent environment that requires control, such as a home automation system.

Filios, Gabriel Katsidimas, et al. [71] Demonstrated the platform and fueling protocol that allows energy accumulation, storage capital, and load system usage to be controlled and completely regulate the system energy inputs and outputs. As the energy management framework can be adapted remotely, based on tracking features, the author generates various harvest profiles to forecast the energy harvested. Similarly, the author makes a charging device profile to forecast potential uses and to approximate energy autonomy. The data method aims to balance current resources in terms of charge cycles and load sustainability and export an energy model that the load device can accept and manage. Drawing on the architecture parameters mentioned, two energy harvesting ICs were simulated to decide whether they could be used with intelligent functions about potential energy and power usage forecasts for the proposed energy storage and power supply device.

Han, Tao Muhammad, et al., [72] Concentrated on the needs of today's smart grids, homes, and businesses to build a deep, intelligent learning system for energy management. For short periods, the author forecasts potential energy usage and provides good coordination between producers and customers. Key contributions include sophisticated, real-time energy management-based devices via widespread cloud-based data server monitoring, optimum technological standardization collection, and a novel sequence-based energy-predicting mechanism with reduced time complexity and lowest error rates. The suggested systems apply to a typical cloud server in an IoT network connecting with the related smart grids to efficiently continue the phenomena of response and energy demand. The author applies numerous preprocessing strategies to resolve various electrical data characteristics, follows an appropriate short-term forecast decision-making algorithm, and implements them on dependable resource-controlled instruments. Even for residential and commercial data sets, the author does detailed experiments and witnesses 0.15 and 3.77 units reduced MSE and RMSE.

Kumar, N Komal Sikamani, et al., [73] Effective dynamic control of household consumables using IoT has been established. The full set-up involves an electronic metering computer, a billing system, LCDs, a base station control unit, a housing station, and a GSM communication module. The energy and amount used will be shown on the LCD screen and transmitted through the Household Station to the base station through GSM. Without the individual having to check periodically for meter readings, the machine also warns them through the mobile device pay for electricity. The device is comfortable and practical to use in domestic areas where electricity is healthy and comfortable for the enterprise and the end-users.

Yang, Ching-Cheng Pandey, et al., [74] proposed a new kind of energy harvesting circuits. This unsolicited electronic counter includes an unsolicited electronic sensor to power an IoT automaton tag. The oscillator was intended to be driven by the discharged capacitances of the charge pump. The gated clock is self-tuned to achieve a precise fit between its input and output impedances to improve circuit efficiency. The chip consists of an integrated circuit with areas of 1.2 square meters implemented using TSMC process T18. This experiment with the DSSC resulted in the maximum power conversion efficiency (PCE) of $77 \%$ for converting electrical energy from the CFLs into the lamp's power. PCE of $70-100 \%$ can be met through a range of lightness of 300 to $1300 \mathrm{~lx}$. With the achieved broad input and output range and the maximum throughput of 200 $\mathrm{mW}$, the 77 per cent power conversion efficiency is the best power conversion efficiency ever reported in this research.

Sedighiani, Shima Singh, et al., [75] Presented the concept and production of electromagnetic energy harvester sensor (EHS) node and bicycle power control incorporated all-in-one kit. An integrated coil within an IC package provides one to seven-and-a-half milliamps of power at eight to forty kilometres per hour. Unlike standard EHS, the transceiver and sensor modules' power supply path is separately provided from $1.8 \mathrm{~V}$, and the on-chip (MCU) of the MCU is operated below/below the threshold. A low power control unit is developed in partnership with MCU to maximize the harvester's capabilities (sense, operation, transmission). The simulation and study of the electromagnetic EHS proposed in response to a time-changing energy source indicate a major increase in our energy availability and the scalability of our EHS compared with cutting-edge technologies. Lowering the size of the processor requires more energy storage capacitors than previous projects.

Haseeb, Khalid Ud Din, et al., [76] Proposed a system for IoT-based wireless sensor networks (WSNs) as a smart agriculture application comprising numerous architecture stages. First, farm sensors gather data and evaluate a collection of cluster heads based on several parameters' decision-making role. The signal's intensity is also calculated on the transmitting connections by using the SNR to achieve reliable and effective data transmission. Second, data transmission from agricultural sensors to base stations (BS) is assured using linear congruent generator recurrence. The simulation findings show that the suggested system has dramatically increased connectivity efficiency in network output by an average of $13.5 \%$, a decrease of $38.5 \%$ in packets, a drop of $13.5 \%$ for network latency, $16 \%$ for energy usage, and $26 \%$ for smart agriculture routing overhead in contrast with other strategies.

Kiat, Wei-Pau Mok, et al. [77] proposed implementing an energy-efficient technique used in IoT applications to support varying performance and energy trade-offs utilizing a reduced instruction set computing (RISC) processor. The processor can be reconfigured into pipeline mode and multi-cycle mode (high computer speed, at the cost of high dynamic power). Switching between modes is done by taking advantage of the partial reconfiguration (PR) function that modern FPGAs bring. A RISC processor has been developed using the microarchitectural level methodology and implemented as an IoT node on FPGA. Experimental findings reveal that reconfigurable microarchitecture enables IoT devices to consume less energy.

Said, Omar Al-Makhadmeh, et al., [78] Introduced an IoT Energy Management Scheme (EMS). Heterogeneous forms of 
energy-controlled nodes are considered in this framework. Three techniques are used in the current EMS. The first approach decreases the number of data distributed through the IoT environment to a minimum. The second approach software the function of the IoT nodes of critical energy. The third approach offers a scenario of fault tolerance to fix imminent energy issues facing IoT nodes. Finally, the proposed EMS is tested by the NS2 network simulator to construct an intense IoT environment simulation. The simulation results demonstrated the efficiency of the proposed EMS regarding the following performance parameters overridden the conventional IoT system: energy usage, number of failed nodes because of lack of energy, throughput, and network life.

Arshad, Junaid Azad, et al. [79] proposed an intrusion detection framework for energy-restricted IoT devices, which form the basis of an industrial IoT (IIoT) ecosystem. The author discusses various topology designs' strategies and feasibility, depending on the degree of top-down and bottom-up control. The author inspected the architecture of the Contiki operating system and validated the proposed architectural design. The research showed that the proposed architecture would reduce energy and coordination overheads while ensuring successful intrusion detection for IIoT systems.

Lork, Clement Li, et al. [80] Built a data-driven and riskbased approach to handling split-type inverter $\mathrm{AC}$ that maximizes efficiency in residential buildings. First, information from related ACs and residential units is aggregated as a minimal imbalance in the data. Then, the Bayesian-ConvolutionalNeural-Networks (BCNNs) are used to model the efficiency and variability of the ACs from aggregated data. Thus, this QLearning-based, reinforcement learning algorithm is dedicated to set-point improvement. Second, a case study will be simulated based on such a system to prove that the uncertainty-aware agent's control behaviour performs well in terms of relief from anxiety and profit optimization. The auto construction design's efficiency can be changed by increasing and decreasing the level of safety improvement.

Li, Wen-Tai Tushar, et al., [81] There are already studies to achieve energy efficiency for the solar water heating system (SWH) in a hospital building situated in Singapore. The author uses the data we have acquired from IoT to gather information on the system's different environmental and operational aspects under consideration, recognize opportunities for optimizing various sub-systems' performance, and establish management mechanisms for the system's effective operation as a whole. Using data gathered by IoT, we do an energy audit to evaluate system components' efficiency and the entire system's performance. Based on the organization's data, appropriate control strategies for the different sub-systems are employed to increase the overall system's performance and reduce the running costs of the SWH. A control mechanism is demonstrated at the SWH site.

Dey, Bishwajit, et al. [82] optimized the scheduling of a distributed low-voltage utility connected microgrid system for distributed energy resources (DERs) is conducted. DERs include coal-fired power plants. Different legislated commandments are considered in choosing dispatch units. Residential buildings commonly sustain their loads during working hours. This research will explore the effects of power loads on the economic benefit of solar microgrid systems. Hybrid solutions involving GREW and SCA have been primarily considered efficient technology, which reduces generation costs. The total cost of generating power was found to increase by $50 \%$ when residential and non-residential loads were considered together. Here, the organization's balanced presence saved $9-17 \%$ of generation costs relative to its autonomous mode use. In summary, the Modified Grey Wolf Optimization-Sine Cosine AlgorithmCrow Search Algorithm (MGWOSCACSA) has been statistically verified against other algorithms.

Jagtap, Shivam Gandhi, et al., [83] Deals with how to eliminate waste most effectively and inexpensively with multiple socioeconomic benefits. The management of the types of waste would use various sensors and actuators for sensing the volume and type of waste. This method helps save resources and efficiency relative to the community's current waste management system and cleanliness.

Aznavi, Sima Fajri, et al., [84] Presented a new Energy Price Tag (EPT) energy management architecture with linked energy store networks to solve the everyday energy management issues in the presence of sporadic applications. The suggested approach compensates for the resultant energy imbalance when an unpredicted intermittent occurs by spreading the stored energy depending on the energy storage systems' EPT. When intermission is over, the energy control system changes its potential operating points on new terms. The suggested framework's reliability is tested over a 24-hour cycle using an energy management system for the average intelligent building. The findings contrast with a simple approach, which does not take EPT into account in managing intermittent systems. The findings comparison validates the suggested approach's feasibility in cost-efficient energy planning of intelligent building components before and after sporadic construction.

Lei, Jinyong Zhou, et al. [85] Proposed an energy optimization approach for controlling the relationship between the smart energy hub (SEH) and energy device consumers. In the system, IoT and energy storage are both considered. First, the SEH models and users are created. The benefit models would then be explored under the impact of energy storage. This paper is the Stackelberg game model, where the SEH serves as the master and users obey. To solve the problem, a double-layer algorithm is proposed. Finally, a case is analyzed to check if the procedure is right. The findings demonstrate that it can be used in the integrated energy system for efficient energy storage, and IoT plays an essential role in sharing knowledge.

Yu, Xiangbin Chu, [86] An energy efficiency (EE), optimization of IoT distributed antenna system with simultaneous wireless information and power transfer (SWIPT) technology over fading networks, has been investigated in which IoT systems are fitted with power splitters for integrating processes of energy harvesting and information decoding by changing transmitting power of each distributed antenna port and power split according to the EE review, the optimization problem is formulated to optimize the EE system, with restriction of maximum transmission capacity and minimum extracted energy for each Distributed Antenna (DA) port. By studying the objective problem's configuration, a PA issue can 
predict the EE optimization problem that combines transmission power allocation (PA) with a power splitting (PS) problem. Based on this, the author has recommended an optimum division of resources without iteration to achieve the desired PA and PS ratios.

Ashiquzzaman, Akm Lee, et al., [87] Reinforcement Learning (RL) is used to create the next generation of IoT devices and create power conservation. A closed grid multisensor resource power management for sensor resource usage has been implemented. Our proposed Deep Q learning model helps IoT devices to save power. This paper only focuses on the promising performance of the energy-efficient sensor calibration and simulation results.

Nguyen, Vanh Khuyen Sheng, et al., [88] The new developments in the internet of things, artificial intelligence, and distributed ledger technology have been built together to create more efficient and intelligent energy storage and energy trading infrastructure in Australia. The platform involves cost-effective IoT devices that can quickly be assimilated, such as smart inverters and sockets connected to already installed devices or renewable sources of power in order to create a smartphone app for intuitive energy consumers to evaluate, program power and monitor and exchange electricity in real-time to improve energy efficiency.

Saxena et al. [89] presented a new type of IoT-based agriculture system using a wireless sensor network (WSN). Different sensors are disposed of irregularly in a given area. Every sensor can sense the data from the environment, collect it, and transfer it to the IoT server. This new system is sound in comparison to other systems because of its advantages. With this system's help, task scheduling, agricultural system monitoring, and watering program are now more efficacious because the cloud can schedule all upcoming tasks and events to the system. The system can automatically schedule any event based on the collected information. Agriculture can be made more accurate and productive by adopting this agricultural production system.

Hossain, Md Liton Abu-Saida, et al., [90] Suggested a more straightforward Space Vector Pulse Width Modulation (SVPWM) for proportional integrals (PI) to eliminate ripples of the output waveform, overcome the problem of the voltage balance and produce improved output waveforms. Wind energy conversion system (WECS), on the other hand, experiences various types of failures, particularly in the dc-link condenser and power converter switching units. These errors will lead to catastrophic failures of the WECS and continuity of power supply unless detected and rectified at the early stages. A new algorithm in the proposed PI-based SVPWM controller is proposed in this paper to locate the fault position in the power converter. Since several wind turbines are installed in remote or offshore areas, the WECS system monitoring must be established by IoT to ensure the system's efficiency. This work presented to track the state of WECS in a real-time environment using an industrial IoT algorithm with an associated hardware prototype.

Mokhtar, Charafeddine Negrou, et al., [91] Presented an innovative solution by merging demand and supply management (DSM) to optimize the particulate swarm and use a traditional dwelling to optimally develop an off-grid hybrid PV-solar diesel-battery system for electrification of residential buildings into arid environments. This proposed HRES would first be modelled by a MATLAB in-house code based on the multi-agent system principle and then adapted, according to the reliability level and renewable energy penetration, by minimizing total net present cost (TNPC) costs. Following HOMER software validation, more techno-economic analysis is carried out, including a sensitive review, taking various battery technologies into account. The findings revealed the following changes when integrating the planned DSM: $\mathrm{RF}=100 \%$ decreases energy demand and TNPC by $7 \%$ and $18 \%$, respectively, in contrast with the single application of supply-side control.

Wang, Lu Jiang, Difei [92] proposed a concept scheme for intelligent building thermal energy consumption control under IoT. The implementation measures are as follows: (i) Create a structural study and composition of the smart monitoring framework for buildings' thermal energy consumption. (ii) For the acquisition of data and real-time data processing for buildings' thermal energy, the DSP integrated signal processor is used to complete the acquisition and data conversion of thermal radiation information. (iii) Create an IoT energy usage information control module and create a wireless sensor network model for monitoring energy consumption to track buildings' consumption of thermal energy intelligently.

Raiker, Gautam A Umanand, et al., [93] Introduced a framework that allows the user to track and manage his loads from a single platform. The framework uses the Internet of Things (IoT) and Cloud Database principles to make the demand-side energy management platform more user-friendly and intuitive. Non-intrusive Load Control (NILM) is used instead of sensors on each Power Socket Outlet for load disaggregation. Disaggregated Load data is saved in the Realtime Database of Google Firebase for quick access from smartphones or the internet. The consumers still have Load Control from the same network, which completes the Load Energy Management loop.

Golpîra, et al., [94] In the presence of transferred loads, an efficient IoT energy management (EM) platform has been implemented for general delivery networks in Smart Cities (SCs). The system's judgment is ideally communicated between its two primary layers; a "core cloud" and the "boundary clouds." The EM of a microgrid (MG), which is shielded by an edge cloud, is directly carried out by its operator and is responsible for optimizing the central cloud's EM by the Distribution System Operator (DSO). The adjustment to the load usage schedule for borders and their peak load hours, based on market energy prices, leads to reduced cloud running costs. With $\mathrm{MG}$ aggregators' maximal trade capacity, the DSO optimizes the overall network running costs to optimize power storage planning by using input parameters for the core cloud optimization issue. The energy storage costs are lower energy prices through consumer buying power and discharged at high energy prices to meet network requirements and meet edge clouds' energy requirements. As a result, the DSO and the MGs use the moving loads and energy storage to fulfil the energy balance at a minimal cost. 
Carli, Raffaele, et al., [95] an IoT-based architecture that would use Model Predictive Control MPC in particular environments. A new algorithm has been devised to consider thermal needs and energy consumption in a closed-loop fashion. All of the sub-systems for sensing, controlling, and actuating are connected to the internet, and end-users are ensured a remote interface with the $\mathrm{AC}$ controller. Besides, this is something commendable in Islam as, according to the legal rule, "prevention is better than cure" and "there should be neither harm nor reciprocating injury." An Internet of Things based control architecture is introduced and tested in a proof-ofconcept building in the Polytechnic of Bari, Italy. The proposed control algorithm is tested in a real-life scenario testing both energy savings and thermal comfort.

Ahrarinouri et al. [96] Explored a multi-agent reinforcement approach to energy conservation in residential areas. Defining the multi-agent system not only raises the scope for independent component demand response systems but also accelerates estimates. We use Q-learning to find the best solution for the given issue of residential energy management. Besides, a scenario-based approach of actual data and correct density functions are used to resolve uncertainties. Deterministic and stochastic numerical simulations justified the feasibility and robustness of the proposed approach. The simulated findings demonstrate that using the proposed strengthening approach contributes to lower prices for customers than traditional energy management systems focused on optimization.

Lu, Qing Lü, et al., [97] Household energy control focused on a smart home energy hub (SREH) whose electricity and natural gas inputs are designed for modern households. The physical features and household expectations suggest pertinent energy-use equipment models as well as management techniques. To distribute energy supply in the SREH, there is a multi-objective optimization challenge, providing schedules for energy-use equipment in addition to categorized standard equipment. Six kinds of unknown actions are modelled as subobjectives in a comfort deviation. The ultimate aim is to minimize energy consumption and the deviation of comfort. Four case studies are then provided to validate the proposed model's feasibility, which increases the sub-objective meaning. The real actions of household consumers finally demonstrate the solidity of the model. To optimize decision-making, sensitivity analysis on the starting time distribution, weighting variables, and the number of unknown scenarios are carried out.

Yu, Qingguang Jiang, [98] Design and implementation of the IoT control strategy in smart microgrid based on the NEZB were proposed. The framework of the intelligent supervisory control and data acquisition (SCADA) system was planned for the online control of energy usage and climate parameters. The power management regulation strategy was introduced. Finally, the planned smart microgrid control strategy is implemented in the NEZB actual project.

\section{Discussion}

From the previous section, it can be seen that researchers have employed different types of techniques in several fields. Investors have issued a list of their recommendations upon studying theirs. Table 1 illustrates the comparison among all reviewed works. The project should include a comparison of the success and commonalities in the methodology of electricity management. The researcher used the Implemented Field method, the Research Used Tools and Technique, and the Significant Satisfied Aims approach to analyze the results.

It is evident from the table that some researcher depended directly on the Residential field. In contrast, another work in the Industry field, rather than the remaining researchers, worked in IoT devices, Agriculture, Smart city, Smart grids, and Communication. Depending on the scientific area of Energy Neutral Plan Scheduling Algorithm, Deep Learning, and Elman (RNN) Model, Deep Q learning, Reinforcement learning, the researcher uses an important technique. Another method is used, such as the Challenge-based Learning Model, Energy management via controllable IoT devices, wireless sensor networks (WSN). Using this methodology and techniques, both researchers have strong structures, frames, and functions in different fields like Industry, Building, Commercial and public services communication, Smart city. However, researchers' trend has been oriented for modern Energy Management fields.

TABLE I. ENERGY MANAGEMENT WITH IOT IN DIFFERENT SECTOR

\begin{tabular}{|c|c|c|c|}
\hline Researcher & $\begin{array}{l}\text { Implemente } \\
\text { d Field }\end{array}$ & $\begin{array}{l}\text { Tools and } \\
\text { Technique Used }\end{array}$ & $\begin{array}{l}\text { Significant } \\
\text { Satisfied Aims }\end{array}$ \\
\hline $\begin{array}{l}\text { Shen, Ruyin } \\
\text { Zhang, et al., } \\
\text { [20] }\end{array}$ & IoT devices & $\begin{array}{l}\text { Block Request } \\
\text { Model, Prefetching } \\
\text { and Caching } \\
\text { Model, Delay and } \\
\text { Energy } \\
\text { Consumption } \\
\text { Model, Energy } \\
\text { Queue Model, }\end{array}$ & $\begin{array}{l}\text { proposed a block } \\
\text { prefetching } \\
\text { framework, } \\
\text { wherein an } \\
\text { energy- } \\
\text { harvesting } \\
\text { powered sensor } \\
\text { can request data } \\
\text { blocks from an } \\
\text { edge server. }\end{array}$ \\
\hline $\begin{array}{l}\text { Garg, Ritu } \\
\text { Garg, } \\
\text { Neha[27] }\end{array}$ & IoT devices & $\begin{array}{l}\text { KL-SUN3W (KL } \\
\text { solar company), } \\
\text { Energy Neutral } \\
\text { Plan Scheduling } \\
\text { Algorithm. }\end{array}$ & $\begin{array}{l}\text { Proposed a } \\
\text { scheduling } \\
\text { algorithm for } \\
\text { balance the } \\
\text { energy produced } \\
\text { by SWEH and an } \\
\text { IoT node energy } \\
\text { consumption } \\
\text { resulting in the } \\
\text { energy-neutral } \\
\text { method. }\end{array}$ \\
\hline $\begin{array}{l}\text { Krishnamoort } \\
\text { hy et al., [66] }\end{array}$ & $\begin{array}{l}\text { Industry, } \\
\text { smart home }\end{array}$ & $\begin{array}{l}\text { cortex-4 32b } \\
\text { MCU, GSM/GPRS } \\
\text { Module, ARM } \\
\text { Controller, Relay } \\
\text { driver, Wireless } \\
\text { transceiver. }\end{array}$ & $\begin{array}{l}\text { A proposed } \\
\text { system for } \\
\text { energy } \\
\text { management } \\
\text { based on the } \\
\text { technology of } \\
\text { (IoT). }\end{array}$ \\
\hline $\begin{array}{l}\text { Bedi, Guneet, } \\
\text { et al., [67] }\end{array}$ & Building & $\begin{array}{l}\text { (RTPIS), Elman } \\
\text { (RNN) Model, } \\
\text { Software } \\
\text { Platforms: online } \\
\text { Audacity Interface, } \\
\text { and MATLAB, } \\
\text { BACnet Protocol. }\end{array}$ & $\begin{array}{l}\text { Created Elman's } \\
\text { recurring neural } \\
\text { network model } \\
\text { and an } \\
\text { exponential } \\
\text { electrical power } \\
\text { prediction model } \\
\text { in a building } \\
\text { environment } \\
\text { powered by IoT. }\end{array}$ \\
\hline
\end{tabular}


M.Sadeeq et al. / Journal of Applied Science and Technology Trends Vol. 02, No. 02, pp. 59 -71, (2021)

\begin{tabular}{|c|c|c|c|}
\hline $\begin{array}{l}\text { Lasso-Lopez, } \\
\text { et al., [68] }\end{array}$ & laboratory & $\begin{array}{l}\text { Challenge-based } \\
\text { Learning Model, } \\
\text { IoT Energy } \\
\text { Monitoring } \\
\text { System. }\end{array}$ & $\begin{array}{l}\text { Presented the } \\
\text { development and } \\
\text { deployment of an } \\
\text { IoT prototype for } \\
\text { energy } \\
\text { monitoring. }\end{array}$ \\
\hline $\begin{array}{l}\text { Almonacid- } \\
\text { Olleros, et al., } \\
\text { [69] }\end{array}$ & $\begin{array}{l}\text { Building, } \\
\text { industry }\end{array}$ & $\begin{array}{l}\text { deep learning } \\
\text { models, CNN, } \\
\text { KNN, LSTM, and } \\
\text { random forest }\end{array}$ & $\begin{array}{l}\text { An IoT system } \\
\text { and a data-driven } \\
\text { approach to wind } \\
\text { forecast have } \\
\text { been described. }\end{array}$ \\
\hline $\begin{array}{l}\text { Avancini, } \\
\text { Danielly } \\
\text { BRodrigues, } \\
\text { et al., [70] }\end{array}$ & $\begin{array}{l}\text { Smart home, } \\
\text { smart } \\
\text { building }\end{array}$ & $\begin{array}{l}\text { Universal } \\
\text { Asynchronous } \\
\text { Receiver/Transmit } \\
\text { ter (UART), } \\
\text { a Wi-Fi radio, } \\
\text { radio node MCU, } \\
\text { Bluetooth focused } \\
\text { on IoT application, } \\
\text { ZigBee or } \\
\text { 6LoWPAN }\end{array}$ & $\begin{array}{l}\text { Built and actual } \\
\text { validation of a } \\
\text { low-cost smart } \\
\text { meter solution } \\
\text { for IoT-based } \\
\text { energy } \\
\text { monitoring. }\end{array}$ \\
\hline $\begin{array}{l}\text { Filios, Gabriel } \\
\text { Katsidimas, et } \\
\text { al., [71] }\end{array}$ & IoT devices & $\begin{array}{l}\text { Ambient energy } \\
\text { harvesting, } \\
\text { wireless power } \\
\text { transfer, } \\
\text { Microcontroller } \\
\text { MCU, }\end{array}$ & $\begin{array}{l}\text { Demonstrated the } \\
\text { platform and } \\
\text { fueling protocol } \\
\text { that allows } \\
\text { energy } \\
\text { accumulation, } \\
\text { storage capital } \\
\text { and load system } \\
\text { usage to be } \\
\text { controlled and } \\
\text { completely } \\
\text { regulate the } \\
\text { system energy } \\
\text { inputs and } \\
\text { outputs. }\end{array}$ \\
\hline $\begin{array}{l}\text { Han, Tao } \\
\text { Muhammad, } \\
\text { et al., [72] }\end{array}$ & $\begin{array}{l}\text { Commercial } \\
\text { and public } \\
\text { services } \\
\text { communicati } \\
\text { on }\end{array}$ & $\begin{array}{l}\text { Deep Learning, } \\
\text { Energy } \\
\text { management via } \\
\text { controllable IoT } \\
\text { devices, Energy } \\
\text { consumption } \\
\text { prediction. }\end{array}$ & $\begin{array}{l}\text { Proposed a deep } \\
\text { learning-based } \\
\text { framework for } \\
\text { intelligent energy } \\
\text { management. }\end{array}$ \\
\hline $\begin{array}{l}\text { Kumar, N } \\
\text { Komal } \\
\text { Sikamani, et } \\
\text { al., [73] }\end{array}$ & $\begin{array}{l}\text { smart } \\
\text { buildings }\end{array}$ & $\begin{array}{l}\text { Arduino Mega, } \\
\text { Arduino Uno, } \\
\text { Current and } \\
\text { Voltage Sensor, } \\
\text { Real-Time Clock } \\
\text { (RTC), LCD and } \\
\text { GSM, }\end{array}$ & $\begin{array}{l}\text { Effective } \\
\text { dynamic control } \\
\text { of household } \\
\text { consumables } \\
\text { using IoT has } \\
\text { been established. }\end{array}$ \\
\hline $\begin{array}{l}\text { Yang, Ching- } \\
\text { Cheng } \\
\text { Pandey, et al., } \\
\text { [74] }\end{array}$ & IoT devices & $\begin{array}{l}\text { The solar driver } \\
\text { and low dropout } \\
\text { regulator circuits, } \\
\text { Bandgap reference } \\
\text { circuit, controller, } \\
\text { Maximum power } \\
\text { point tracking } \\
\text { (MPPT) Circuit, } \\
\text { Output hysteresis } \\
\text { control circuit, } \\
\text { cross-coupled } \\
\text { charge pump } \\
\text { Circuit. }\end{array}$ & $\begin{array}{l}\text { Proposed a new } \\
\text { efficient energy } \\
\text { harvesting device } \\
\text { with a cross- } \\
\text { coupled charge } \\
\text { pump for a } \\
\text { flexible dye- } \\
\text { sensitized solar } \\
\text { cell to power a } \\
\text { battery-less IoT. } \\
\text { Tag. }\end{array}$ \\
\hline $\begin{array}{l}\text { Sedighiani, } \\
\text { Shima Singh, } \\
\text { et al.,[75] }\end{array}$ & industry & $\begin{array}{l}\text { microcontroller } \\
\text { (MCU), voltage } \\
\text { delivery, storage } \\
\text { elements, control } \\
\text { unit, electronic }\end{array}$ & $\begin{array}{l}\text { Presented the } \\
\text { concept and } \\
\text { production of the } \\
\text { Electromagnetic } \\
\text { Energy Harvester } \\
\text { sensor (EHS) } \\
\text { node and bicycle }\end{array}$ \\
\hline
\end{tabular}

\begin{tabular}{|c|c|c|c|}
\hline & & $\begin{array}{l}\text { loads sensors, } \\
\text { transceiver. }\end{array}$ & $\begin{array}{l}\text { power control } \\
\text { integrated kit. }\end{array}$ \\
\hline $\begin{array}{l}\text { Haseeb, } \\
\text { Khalid Ud } \\
\text { Din, et al., } \\
\text { [76] }\end{array}$ & agricultural & $\begin{array}{l}\text { wireless sensor } \\
\text { networks, base } \\
\text { stations. }\end{array}$ & $\begin{array}{l}\text { Proposed a } \\
\text { system for IoT- } \\
\text { based wireless } \\
\text { sensor networks } \\
\text { (WSNs) as a } \\
\text { smart agriculture } \\
\text { application } \\
\text { comprising } \\
\text { numerous } \\
\text { architecture } \\
\text { stages. }\end{array}$ \\
\hline $\begin{array}{l}\text { Kiat, Wei-Pau } \\
\text { Mok, et al., } \\
\text { [77] }\end{array}$ & IoT devices & $\begin{array}{l}\text { micro-architectural } \\
\text { FPGA, (analog } \\
\text { sensor) or GPIO } \\
\text { (digital sensor), 5- } \\
\text { stage 32-bit MIPS } \\
\text { Instruction Set } \\
\text { Architecture (ISA) } \\
\text { compatible } \\
\text { processor, } \\
\text { (ZigBee). }\end{array}$ & $\begin{array}{l}\text { Introduced a } \\
\text { reconfigurable } \\
\text { micro- } \\
\text { architectural } \\
\text { level technique to } \\
\text { provide support } \\
\text { for IoT } \\
\text { applications with } \\
\text { varying } \\
\text { performance and } \\
\text { energy trade } \\
\text { criteria via a } \\
\text { Reduced } \\
\text { Instruction Set } \\
\text { Computing } \\
\text { (RISC) } \\
\text { processor. }\end{array}$ \\
\hline $\begin{array}{l}\text { Said, Omar Al } \\
\text { Makhadmeh, } \\
\text { et al., [78] }\end{array}$ & $\begin{array}{l}\text { IoT } \\
\text { environment }\end{array}$ & Sensors, RFID & $\begin{array}{l}\text { Introduced an } \\
\text { IoT Energy } \\
\text { Management } \\
\text { Scheme (EMS). } \\
\text { Heterogeneous } \\
\text { forms of energy- } \\
\text { controlled nodes } \\
\text { are considered in } \\
\text { this framework. }\end{array}$ \\
\hline $\begin{array}{l}\text { Arshad, } \\
\text { Junaid Azad, } \\
\text { et al., [79] }\end{array}$ & Industry & $\begin{array}{l}\text { device-level } \\
\text { detection module, } \\
\text { Message Queuing } \\
\text { Telemetry } \\
\text { Transport (MQTT) } \\
\text { protocol. }\end{array}$ & $\begin{array}{l}\text { Proposed } \\
\text { Intrusion } \\
\text { Detection } \\
\text { Framework for } \\
\text { Energy- } \\
\text { Restricted IoT } \\
\text { Devices, which } \\
\text { form the basis of } \\
\text { an Industrial IoT } \\
\text { (IIoT) ecosystem. }\end{array}$ \\
\hline $\begin{array}{l}\text { Lork, Clement } \\
\text { Li, et al., [80] }\end{array}$ & residential & $\begin{array}{l}\text { Bayesian- } \\
\text { Convolutional- } \\
\text { Neural-Networks, } \\
\text { Q-learning-based } \\
\text { reinforcement } \\
\text { learning algorithm }\end{array}$ & $\begin{array}{l}\text { Proposed a data- } \\
\text { driven approach } \\
\text { to managing } \\
\text { split-type } \\
\text { inverter ACs for } \\
\text { residential } \\
\text { buildings. }\end{array}$ \\
\hline $\begin{array}{l}\text { Li, Wen-Tai } \\
\text { Tushar, et al., } \\
\text { [81] }\end{array}$ & residential & $\begin{array}{l}\text { The IoT-based } \\
\text { monitoring system, } \\
\text { Solar irradiance } \\
\text { sensor, Flowmeter, } \\
\text { Temperature } \\
\text { sensor, Status } \\
\text { sensor. }\end{array}$ & $\begin{array}{l}\text { Developed a } \\
\text { variety of control } \\
\text { systems to make } \\
\text { inefficient sub- } \\
\text { systems more } \\
\text { efficient Leaders } \\
\text { of SWH. }\end{array}$ \\
\hline $\begin{array}{l}\text { Dey, } \\
\text { Bishwajit, et } \\
\text { al., [82] }\end{array}$ & residential & $\begin{array}{l}\text { Modified } \\
\text { Greywolf } \\
\text { Optimization, } \\
\text { Crow Search } \\
\text { Algorithm, Sine } \\
\text { Cosine Algorithm. }\end{array}$ & $\begin{array}{l}\text { Verified } \\
\text { (MGWOSCACS } \\
\text { A) algorithms. }\end{array}$ \\
\hline
\end{tabular}


M.Sadeeq et al. / Journal of Applied Science and Technology Trends Vol. 02, No. 02, pp. 59 -71, (2021)

\begin{tabular}{|c|c|c|c|c|c|c|c|}
\hline \multirow{2}{*}{$\begin{array}{l}\text { Jagtap, } \\
\text { Shivam } \\
\text { Gandhi, et al., } \\
\text { [83] }\end{array}$} & \multirow[t]{2}{*}{ Smart city } & \multirow{2}{*}{$\begin{array}{l}\text { Ultrasonic Sensor, } \\
\text { Moisture Sensor, } \\
\text { GSM Module, }\end{array}$} & \multirow{2}{*}{$\begin{array}{l}\text { Deals with the } \\
\text { idea of waste } \\
\text { control and the } \\
\text { intelligent waste } \\
\text { management } \\
\text { system with } \\
\text { larger } \\
\text { socioeconomic } \\
\text { advantages. }\end{array}$} & & & & $\begin{array}{l}\text { wireless sensor } \\
\text { networks (WSN). }\end{array}$ \\
\hline & & & & \multirow[t]{2}{*}{$\begin{array}{l}\text { Hossain, Md } \\
\text { Liton Abu- } \\
\text { Siada, [90] }\end{array}$} & \multirow[t]{2}{*}{ industry } & \multirow{2}{*}{$\begin{array}{l}\text { global packet radio } \\
\text { service (GPRS), } \\
\text { Arduino IDE, } \\
\text { Adafruit FONA } \\
\text { Library (AFL), } \\
\text { Software Serial } \\
\text { Library (SSL), and } \\
\text { Liquid Crystal } \\
\text { Library (LCL) }\end{array}$} & \multirow{2}{*}{$\begin{array}{l}\text { Suggested a } \\
\text { simpler space } \\
\text { vector pulse } \\
\text { width modulation } \\
\text { (SVPWM) for } \\
\text { proportional } \\
\text { integrals (PI) to } \\
\text { eliminate the } \\
\text { output waveform } \\
\text { ripples, } \\
\text { overcome the } \\
\text { voltage balance } \\
\text { problem, and } \\
\text { produce } \\
\text { improved output } \\
\text { waveforms. }\end{array}$} \\
\hline \multirow[t]{2}{*}{$\begin{array}{l}\text { Aznavi, Sima } \\
\text { Fajri, et al., } \\
\text { [84] }\end{array}$} & \multirow[t]{2}{*}{$\begin{array}{l}\text { Smart } \\
\text { buildings }\end{array}$} & \multirow[t]{2}{*}{ Controller, sensor } & \multirow{2}{*}{$\begin{array}{l}\text { Presented a new } \\
\text { Energy Price Tag } \\
\text { (EPT) energy } \\
\text { management } \\
\text { architecture with } \\
\text { linked energy } \\
\text { store networks to } \\
\text { solve the } \\
\text { everyday energy } \\
\text { management } \\
\text { issues in sporadic } \\
\text { applications. }\end{array}$} & & & & \\
\hline & & & & \multirow{2}{*}{$\begin{array}{l}\text { Mokhtara, } \\
\text { Charafeddine } \\
\text { Negrou, et al., } \\
\text { [91] }\end{array}$} & \multirow[t]{2}{*}{ residential } & \multirow[t]{2}{*}{ MATLAB code } & \multirow{2}{*}{$\begin{array}{l}\text { Presented an } \\
\text { innovative } \\
\text { solution by } \\
\text { merging demand } \\
\text { and supply } \\
\text { management } \\
\text { (DSM) to } \\
\text { optimize the } \\
\text { particulate } \\
\text { swarm and use a } \\
\text { traditional } \\
\text { dwelling. }\end{array}$} \\
\hline \multirow[t]{2}{*}{$\begin{array}{l}\text { Lei, Jinyong } \\
\text { Zhou, et al., } \\
\text { [85] }\end{array}$} & \multirow[t]{2}{*}{ industry } & \multirow[t]{2}{*}{$\begin{array}{l}\text { Stackelberg game, } \\
\text { two-layer } \\
\text { distributed } \\
\text { optimization } \\
\text { method }\end{array}$} & \multirow[t]{2}{*}{$\begin{array}{l}\text { Proposed an } \\
\text { energy } \\
\text { optimization } \\
\text { approach for } \\
\text { controlling the } \\
\text { relationship } \\
\text { between the } \\
\text { smart energy hub } \\
\text { (SEH) and } \\
\text { energy device } \\
\text { consumers. }\end{array}$} & & & & \\
\hline & & & & \multirow{2}{*}{$\begin{array}{l}\text { Wang, Lu } \\
\text { Jiang, Difei } \\
\text { [92] }\end{array}$} & \multirow[t]{2}{*}{ residential } & \multirow{2}{*}{$\begin{array}{l}\text { DSP integrated } \\
\text { signal processor, } \\
\text { real-time } \\
\text { information } \\
\text { processing, } \\
\text { intelligent wireless } \\
\text { gateway, wireless } \\
\text { sensor network } \\
\text { model. }\end{array}$} & \multirow{2}{*}{$\begin{array}{l}\text { proposed a } \\
\text { concept scheme } \\
\text { for intelligent } \\
\text { building thermal } \\
\text { energy } \\
\text { consumption } \\
\text { control under IoT }\end{array}$} \\
\hline \multirow[t]{2}{*}{$\begin{array}{l}\text { Yu, Xiangbin } \\
\text { Chu, [86] }\end{array}$} & \multirow[t]{2}{*}{$\begin{array}{l}\text { communicati } \\
\text { on }\end{array}$} & \multirow[t]{2}{*}{$\begin{array}{l}\text { Optimal Scheme } \\
\text { and Algorithm, } \\
\text { Optimal Allocation } \\
\text { Algorithm, }\end{array}$} & \multirow{2}{*}{$\begin{array}{l}\text { An energy } \\
\text { efficiency (EE), } \\
\text { optimization of } \\
\text { IoT distributed } \\
\text { antenna system } \\
\text { with } \\
\text { simultaneous } \\
\text { wireless } \\
\text { information and } \\
\text { power transfer } \\
\text { (SWIPT) } \\
\text { technology over } \\
\text { fading networks, } \\
\text { has been } \\
\text { investigated. }\end{array}$} & & & & \\
\hline & & & & $\begin{array}{l}\text { Raiker, } \\
\text { Gautam A } \\
\text { Umanand, et } \\
\text { al., [93] }\end{array}$ & industry & $\begin{array}{l}\text { Texas Instruments } \\
\text { make } \\
\text { MSP430F67641, } \\
\text { WIFI + } \\
\text { Microcontroller } \\
\text { (MCU) SoC Unit } \\
\text { CC3200,(NILM) } \\
\text { Algorithm. }\end{array}$ & $\begin{array}{l}\text { Introduced a } \\
\text { framework that } \\
\text { allows the user to } \\
\text { track and manage } \\
\text { his loads from a } \\
\text { single platform. }\end{array}$ \\
\hline \multirow{2}{*}{$\begin{array}{l}\text { Ashiquzzama } \\
\text { n, Akm Lee, } \\
\text { et al., [87] }\end{array}$} & \multirow[t]{2}{*}{ IoT devices } & \multirow{2}{*}{$\begin{array}{l}\text { Deep Q learning, } \\
\text { Reinforcement } \\
\text { learning }\end{array}$} & \multirow{2}{*}{$\begin{array}{l}\text { a new style of } \\
\text { power } \\
\text { conservation has } \\
\text { been explored }\end{array}$} & \multirow{3}{*}{$\begin{array}{l}\text { Golpîra, et al., } \\
\text { [94] }\end{array}$} & \multirow{3}{*}{ Smart city } & \multirow{3}{*}{$\begin{array}{l}\text { Microgrid } \\
\text { aggregator (MGA), } \\
\text { distribution system } \\
\text { operator (DSO). }\end{array}$} & \multirow{3}{*}{$\begin{array}{l}\text { In the presence } \\
\text { of transferred } \\
\text { loads, an } \\
\text { efficient IoT } \\
\text { energy } \\
\text { management } \\
\text { (EM) platform } \\
\text { has been } \\
\text { implemented for } \\
\text { general delivery } \\
\text { networks in } \\
\text { Smart Cities } \\
\text { (SCs). }\end{array}$} \\
\hline & & & & & & & \\
\hline \multirow[t]{2}{*}{$\begin{array}{l}\text { Nguyen, Vanh } \\
\text { Khuyen } \\
\text { Sheng, et al., } \\
\text { [88] }\end{array}$} & \multirow[t]{2}{*}{ Smart grids } & \multirow[t]{2}{*}{$\begin{array}{l}\text { Smart Solar } \\
\text { Energy } \\
\text { Management, } \\
\text { Technological } \\
\text { Feasibility } \\
\text { Verification, } \\
\text { Distributed Energy } \\
\text { Trading. }\end{array}$} & $\begin{array}{l}\text { Build a mobile } \\
\text { interface to } \\
\text { provide energy } \\
\text { users with } \\
\text { intuitive } \\
\text { analytics, } \\
\text { programmable } \\
\text { power, and real- } \\
\text { time energy }\end{array}$ & & & & \\
\hline & & & $\begin{array}{l}\text { tracking and } \\
\text { trading to boost } \\
\text { their energy } \\
\text { quality. }\end{array}$ & $\begin{array}{l}\text { Carli, } \\
\text { Raffaele, et } \\
\text { al., [95] }\end{array}$ & $\begin{array}{l}\text { Smart } \\
\text { Buildings }\end{array}$ & $\begin{array}{l}\text { IoT based control } \\
\text { system } \\
\text { architecture, IoT } \\
\text { based control } \\
\text { system } \\
\text { architecture. }\end{array}$ & $\begin{array}{l}\text { Proposed IoT- } \\
\text { based } \\
\text { architecture to } \\
\text { incorporate } \\
\text { Heating } \\
\text { Ventilation and }\end{array}$ \\
\hline $\begin{array}{l}\text { Saxena et al., } \\
\text { [89] }\end{array}$ & agriculture & $\begin{array}{l}\text { Global Positioning } \\
\text { System (GPS), } \\
\text { Wireless sensor } \\
\text { networks (WSN) }\end{array}$ & $\begin{array}{l}\text { Demonstrated the } \\
\text { feasibility of an } \\
\text { IoT-based } \\
\text { agriculture } \\
\text { system using }\end{array}$ & & & & $\begin{array}{l}\text { Air Conditioning } \\
\text { (HVAC), Model } \\
\text { Predictive } \\
\text { Control (MPC) } \\
\text { systems in }\end{array}$ \\
\hline
\end{tabular}




\begin{tabular}{|l|l|l|l|}
\hline & & & $\begin{array}{l}\text { specific } \\
\text { environments. }\end{array}$ \\
\hline $\begin{array}{l}\text { Ahrarinouri et } \\
\text { al., [96] }\end{array}$ & residential & $\begin{array}{l}\text { Q-learning, Multi- } \\
\text { Agents System, }\end{array}$ & $\begin{array}{l}\text { Explored a multi- } \\
\text { agent } \\
\text { reinforcement } \\
\text { approach to } \\
\text { energy } \\
\text { conservation in } \\
\text { residential areas. }\end{array}$ \\
\hline $\begin{array}{l}\text { Lu, Qing Lü, } \\
\text { et al., [97] }\end{array}$ & residential & $\begin{array}{l}\text { shiftable and } \\
\text { interruptible loads } \\
\text { (SIL), shiftable } \\
\text { and non- } \\
\text { interruptible loads } \\
\text { (SNIL) }\end{array}$ & $\begin{array}{l}\text { Household } \\
\text { energy control } \\
\text { focused on a } \\
\text { smart home } \\
\text { energy hub } \\
\text { (SREH) whose } \\
\text { electricity and } \\
\text { natural gas inputs } \\
\text { are designed for } \\
\text { modern } \\
\text { households. }\end{array}$ \\
\hline $\begin{array}{l}\text { Yu, } \\
\text { Qingguang }\end{array}$ & residential & $\begin{array}{l}\text { Smart Microgrid, } \\
\text { Jiang, [98] } \\
\text { directional AC/DC } \\
\text { Inverter, Control } \\
\text { Strategy of Solar } \\
\text { DC/DC Inverter. }\end{array}$ & $\begin{array}{l}\text { The design and } \\
\text { implementation } \\
\text { of the IoT control } \\
\text { strategy in smart } \\
\text { microgrid based } \\
\text { on the NEZB } \\
\text { were proposed. }\end{array}$ \\
\hline & & & \\
& & &
\end{tabular}

\section{CONCLUSION}

This paper addressed important management methods to reduce energy consumption. The literature review indicated that various active mechanisms contribute to energy management achievement. These areas include residential, industrial, agricultural, smart city, smart buildings, smart grid, communication, Internet of Things (IoT) devices, and Internet of Things environment. There are many tools in this area, such as MATLAB, DSP integrated signal processor, real-time information processing, intelligent wireless gateway, wireless sensor network model, microcontroller, and other types of computing tools (MCU). To attain the goal, various techniques have been successfully used by the researchers (WSN). Today the researchers continue to focus on the residential, industry, agriculture, and smart city aspects. Both solutions of Energy Management Scheme (EMS) and IoT-based architecture for Heating Ventilation and Air Conditioning (HVAC) have been developed to incorporate SMART energy hub and smart energy devices, respectively. Adding to that, it can conclude that IoT is the most suitable technique for energy management and consumption. Also, to control and monitor the distributed building.

\section{REFERENCES}

[1] P. Asghari, A. M. Rahmani, and H. H. S. Javadi, "Internet of Things applications: A systematic review," Computer Networks, vol. 148, pp. 241-261, 2019.

[2] M. A. Sadeeq, S. R. Zeebaree, R. Qashi, S. H. Ahmed, and K. Jacksi, "Internet of Things security: a survey," in 2018 International Conference on Advanced Science and Engineering (ICOASE), 2018, pp. 162-166.

[3] S. Zeebaree and H. M. Yasin, "Arduino based remote controlling for home: power saving, security and protection," International Journal of Scientific \& Engineering Research, vol. 5, pp. 266-272, 2014.

[4] A. A. Salih, S. R. Zeebaree, A. S. Abdulraheem, R. R. Zebari, M. A. Sadeeq, and O. M. Ahmed, "Evolution of Mobile Wireless
Communication to 5G Revolution," Technology Reports of Kansai University, vol. 62, pp. 2139-2151, 2020.

[5] C. Han, J. M. Jornet, E. Fadel, and I. F. Akyildiz, "A cross-layer communication module for the Internet of Things," Computer Networks, vol. 57 , pp. 622-633, 2013.

[6] A. Tiwary, M. Mahato, A. Chidar, M. K. Chandrol, M. Shrivastava, and M. Tripathi, "Internet of Things (IoT): Research, architectures and applications," International Journal on Future Revolution in Computer Science \& Communication Engineering, vol. 4, pp. 23-27, 2018.

[7] V. H. Puar, C. M. Bhatt, D. M. Hoang, and D.-N. Le, "Communication in Internet of Things," in Information Systems Design and Intelligent Applications, ed: Springer, 2018, pp. 272-281.

[8] S. R. Zeebaree, H. M. Shukur, and B. K. Hussan, "Human resource management systems for enterprise organizations: A review," Periodicals of Engineering and Natural Sciences (PEN), vol. 7, pp. 660-669, 2019.

[9] K. E. Jeon, J. She, P. Soonsawad, and P. C. Ng, "Ble beacons for internet of things applications: Survey, challenges, and opportunities," IEEE Internet of Things Journal, vol. 5, pp. 811-828, 2018.

[10] A. I. Abdulla, A. S. Abdulraheem, A. A. Salih, M. A. Sadeeq, A. J. Ahmed, B. M. Ferzor, et al., "Internet of Things and Smart Home Security," Technol. Rep. Kansai Univ, vol. 62, pp. 2465-2476, 2020.

[11] A. S. Abdulraheem, A. A. Salih, A. I. Abdulla, M. A. Sadeeq, N. O. Salim, H. Abdullah, et al., "Home automation system based on IoT," 2020.

[12] F. Gianni, S. Mora, and M. Divitini, "RapIoT toolkit: Rapid prototyping of collaborative Internet of Things applications," Future Generation Computer Systems, vol. 95, pp. 867-879, 2019.

[13] M. S. Aktas and M. Astekin, "Provenance aware run-time verification of things for self-healing Internet of Things applications," Concurrency and Computation: Practice and Experience, vol. 31, p. e4263, 2019.

[14] A. M. Abdulazeez, S. R. Zeebaree, and M. A. Sadeeq, "Design and Implementation of Electronic Student Affairs System," Academic Journal of Nawroz University, vol. 7, pp. 66-73, 2018.

[15] A. B. Sallow, S. R. Zeebaree, R. R. Zebari, M. R. Mahmood, M. B. Abdulrazzaq, and M. A. Sadeeq, "Vaccine Tracker/SMS Reminder System: Design and Implementation."

[16] A. Maiti, T. Byrne, and A. A. Kist, "Teaching Internet of Things in a Collaborative Laboratory Environment," in 2019 5th Experiment International Conference (exp. at'19), 2019, pp. 193-198.

[17] P. Ganguly, "Selecting the right IoT cloud platform," in 2016 International Conference on Internet of Things and Applications (IOTA), 2016, pp. 316-320.

[18] M. R. Stead, P. Coulton, J. G. Lindley, and C. Coulton, "The little book of sustainability for the Internet of Things," ed: Imagination Lancaster, 2019.

[19] N. Hossein Motlagh, M. Mohammadrezaei, J. Hunt, and B. Zakeri, "Internet of Things (IoT) and the energy sector," Energies, vol. 13, p. 494, 2020.

[20] R. Shen, D. Zhang, Y. Zhang, T. Yang, and Y. Zhang, "A Block Prefetching Framework for Energy Harvesting IoT Devices," IEEE Internet of Things Journal, vol. 7, pp. 3427-3440, 2020.

[21] D. A. Hasan, B. K. Hussan, S. R. Zeebaree, D. M. Ahmed, O. S. Kareem, and M. A. Sadeeq, "The Impact of Test Case Generation Methods on the Software Performance: A Review," International Journal of Science and Business, vol. 5, pp. 33-44, 2021.

[22] C. Iwendi, P. K. R. Maddikunta, T. R. Gadekallu, K. Lakshmanna, A. K. Bashir, and M. J. Piran, "A metaheuristic optimization approach for energy efficiency in the IoT networks," Software: Practice and Experience, 2020.

[23] A. Zouinkhi, H. Ayadi, T. Val, B. Boussaid, and M. N. Abdelkrim, "Automanagement of energy in IoT networks," International Journal of Communication Systems, vol. 33, p. e4168, 2020.

[24] I. U. Din, S. Hassan, A. Almogren, F. Ayub, and M. Guizani, "PUC: Packet update caching for energy efficient IoT-based information-centric networking," Future Generation Computer Systems, vol. 111, pp. 634643, 2020.

[25] S. S. Dash, C. Lakshmi, S. Das, and B. K. Panigrahi, Artificial intelligence and evolutionary computations in engineering systems: Springer, 2020. 
[26] W. Shafik, S. M. Matinkhah, and M. Ghasemzadeh, "Internet of ThingsBased Energy Management, Challenges, and Solutions in Smart Cities," Journal of Communications Technology, Electronics and Computer Science, vol. 27, pp. 1-11, 2020.

[27] R. Garg and N. Garg, "Energy Management in a Multi-Source Energy Harvesting IoT System," Journal of Information Technology Research (JITR), vol. 13, pp. 42-59, 2020.

[28] L. M. Haji, O. M. Ahmad, S. R. Zeebaree, H. I. Dino, R. R. Zebari, and H. M. Shukur, "Impact of cloud computing and internet of things on the future internet," Technology Reports of Kansai University, vol. 62, pp. 2179-2190, 2020

[29] M. M. Sadeeq, N. M. Abdulkareem, S. R. Zeebaree, D. M. Ahmed, A. S. Sami, and R. R. Zebari, "IoT and Cloud Computing Issues, Challenges and Opportunities: A Review," Qubahan Academic Journal, vol. 1, pp. 17, 2021.

[30] R. P. Singh, M. Javaid, A. Haleem, and R. Suman, "Internet of things (IoT) applications to fight against COVID-19 pandemic," Diabetes \& Metabolic Syndrome: Clinical Research \& Reviews, vol. 14, pp. 521-524, 2020.

[31] J. An, X.-L. Gui, and X. He, "Study on the architecture and key technologies for internet of things," Advances in Biomedical Engineering, vol. 11, p. 329, 2012.

[32] Z. Yue, W. Sun, P. Li, M. U. Rehman, and X. Yang, "Internet of things: Architecture, technology and key problems in implementation," in 2015 8th International Congress on Image and Signal Processing (CISP), 2015, pp. 1298-1302.

[33] A.-L. Zhang, "Research on the architecture of internet of things applied in coal mine," in 2016 International Conference on Information System and Artificial Intelligence (ISAI), 2016, pp. 21-23.

[34] S. S. R. Zeebaree, S. Ameen, and M. Sadeeq, "Social Media Networks Security Threats, Risks and Recommendation: A Case Study in the Kurdistan Region," International Journal of Innovation, Creativity and Change, vol. 13, pp. 349-365, 2020.

[35] A. Ramamurthy and P. Jain, "The internet of things in the power sector opportunities in Asia and the Pacific," 2017.

[36] M. J. Berthelot, N. Lasensky, and P. Somers, "The Board's Role in Monitoring Strategy: Lessons Learned from General Electric," 2019.

[37] A. Sharif, S. A. Raza, I. Ozturk, and S. Afshan, "The dynamic relationship of renewable and nonrenewable energy consumption with carbon emission: a global study with the application of heterogeneous panel estimations," Renewable Energy, vol. 133, pp. 685-691, 2019.

[38] iea, "www.iea.org," 2021.

[39] P. K. Sharma, N. Kumar, and J. H. Park, "Blockchain Technology Toward Green IoT: Opportunities and Challenges," IEEE Network, 2020.

[40] P. Chithaluru, F. Al-Turjman, M. Kumar, and T. Stephan, "I-AREOR: An Energy-balanced Clustering Protocol for implementing Green IoT in smart cities," Sustainable Cities and Society, p. 102254, 2020.

[41] W. Ejaz and A. Anpalagan, "Internet of things for smart cities: overview and key challenges," in Internet of Things for Smart Cities, ed: Springer, 2019, pp. 1-15.

[42] A. B. Sallow, M. Sadeeq, R. R. Zebari, M. B. Abdulrazzaq, M. R. Mahmood, H. M. Shukur, et al., "An Investigation for Mobile Malware Behavioral and Detection Techniques Based on Android Platform," IOSR Journal of Computer Engineering (IOSR-JCE), vol. 22, pp. 14-20.

[43] S. P. Mohanty, U. Choppali, and E. Kougianos, "Everything you wanted to know about smart cities: The internet of things is the backbone," IEEE Consumer Electronics Magazine, vol. 5, pp. 60-70, 2016.

[44] H. M. Yasin, S. R. Zeebaree, and I. M. Zebari, "Arduino Based Automatic Irrigation System: Monitoring and SMS Controlling," in 2019 4th Scientific International Conference Najaf (SICN), 2019, pp. 109-114.

[45] L. Tightiz and H. Yang, "A Comprehensive Review on IoT Protocols' Features in Smart Grid Communication," Energies, vol. 13, p. 2762, 2020.

[46] Z. Hameed, F. Ahmad, S. ur Rehman, and Z. Ghafoor, "IoT Based Communication Technologies to Integrate and Maximize the Efficiency of Renewable Energy Resources with Smart Grid," in 2020 International Conference on Computing and Information Technology (ICCIT-1441), 2020, pp. 1-5.
[47] L. M. Haji, S. Zeebaree, O. M. Ahmed, A. B. Sallow, K. Jacksi, and R. R. Zeabri, "Dynamic resource allocation for distributed systems and cloud computing," TEST Engineering \& Management, vol. 83, pp. 2241722426, 2020.

[48] Z. S. Ageed, R. K. Ibrahim, and M. A. Sadeeq, "Unified Ontology Implementation of Cloud Computing for Distributed Systems," Current Journal of Applied Science and Technology, pp. 82-97, 2020.

[49] Z. N. Rashid, S. R. Zebari, K. H. Sharif, and K. Jacksi, "Distributed cloud computing and distributed parallel computing: A review," in 2018 International Conference on Advanced Science and Engineering (ICOASE), 2018, pp. 167-172.

[50] Z. N. Rashid, S. R. Zeebaree, and A. Shengul, "Design and analysis of proposed remote controlling distributed parallel computing system over the cloud," in 2019 International Conference on Advanced Science and Engineering (ICOASE), 2019, pp. 118-123.

[51] S. R. Zebari and N. O. Yaseen, "Effects of Parallel Processing Implementation on Balanced Load-Division Depending on Distributed Memory Systems," J. Univ. Anbar Pure Sci, vol. 5, pp. 50-56, 2011.

[52] Z. Ageed, M. R. Mahmood, M. Sadeeq, M. B. Abdulrazzaq, and H. Dino, "Cloud computing resources impacts on heavy-load parallel processing approaches," IOSR Journal of Computer Engineering (IOSR-JCE), vol. 22, pp. 30-41, 2020.

[53] D. H. Maulud, S. R. Zeebaree, K. Jacksi, M. A. M. Sadeeq, and K. H. Sharif, "State of Art for Semantic Analysis of Natural Language Processing," Qubahan Academic Journal, vol. 1, 2021.

[54] O. Alzakholi, H. Shukur, R. Zebari, S. Abas, and M. Sadeeq, "Comparison among cloud technologies and cloud performance," Journal of Applied Science and Technology Trends, vol. 1, pp. 40-47, 2020.

[55] H. Shukur, S. R. Zeebaree, A. J. Ahmed, R. R. Zebari, O. Ahmed, B. S. A. Tahir, et al., "A State of Art Survey for Concurrent Computation and Clustering of Parallel Computing for Distributed Systems," Journal of Applied Science and Technology Trends, vol. 1, pp. 148-154, 2020.

[56] M. A. Sulaiman, M. Sadeeq, A. S. Abdulraheem, and A. I. Abdulla, "Analyzation Study for Gamification Examination Fields," Technol. Rep. Kansai Univ, vol. 62, pp. 2319-2328, 2020.

[57] S. R. Zeebaree, H. M. Shukur, L. M. Haji, R. R. Zebari, K. Jacksi, and S, M. Abas, "Characteristics and analysis of hadoop distributed systems," Technology Reports of Kansai University, vol. 62, pp. 1555-1564, 2020.

[58] P. Y. Abdullah, S. R. Zeebaree, K. Jacksi, and R. R. Zeabri, "An hrm system for small and medium enterprises (sme) s based on cloud computing technology," International Journal of ResearchGRANTHAALAYAH, vol. 8, pp. 56-64, 2020.

[59] P. Y. Abdullah, S. R. Zeebaree, H. M. Shukur, and K. Jacksi, "HRM system using cloud computing for Small and Medium Enterprises (SMEs)," Technology Reports of Kansai University, vol. 62, p. 04, 2020.

[60] Y. S. Jghef and S. Zeebaree, "State of Art Survey for Significant Relations between Cloud Computing and Distributed Computing," International Journal of Science and Business, vol. 4, pp. 53-61, 2020.

[61] M. Sadeeq, A. I. Abdulla, A. S. Abdulraheem, and Z. S. Ageed, "Impact of Electronic Commerce on Enterprise Business," Technol. Rep. Kansai Univ, vol. 62, pp. 2365-2378, 2020.

[62] C. M. Mohammed and S. R. Zebaree, "Sufficient Comparison Among Cloud Computing Services: IaaS, PaaS, and SaaS: A Review," International Journal of Science and Business, vol. 5, pp. 17-30, 2021.

[63] A. A. Yazdeen, S. R. Zeebaree, M. M. Sadeeq, S. F. Kak, O. M. Ahmed, and R. R. Zebari, "FPGA Implementations for Data Encryption and Decryption via Concurrent and Parallel Computation: A Review," Qubahan Academic Journal, vol. 1, pp. 8-16, 2021.

[64] S. R. Zeebaree, "Remote Controlling Distributed Parallel Computing System over the Cloud (RCDPCSC)," in 2020 3rd International Conference on Engineering Technology and its Applications (IICETA), 2020, pp. 258-258.

[65] Z. N. Rashid, S. R. Zeebaree, and A. Sengur, "Novel Remote Parallel Processing Code-Breaker System via Cloud Computing."

[66] R. Krishnamoorthy, S. Aswini, and C. Guna, "Design and Implementation of IoT based Energy Management System with Data Acquisition," in 2020 7th International Conference on Smart Structures and Systems (ICSSS), 2020, pp. 1-5. 
[67] G. Bedi, G. K. Venayagamoorthy, and R. Singh, "Development of an IoT Driven Building Environment for Prediction of Electric Energy Consumption," IEEE Internet of Things Journal, 2020.

[68] O. Lasso-Lopez, C. González-Espinoza, C. Lozoya, A. Venzor-Mendoza, A. Dávila-Villalobos, and C. Royo-Noble, "Implementing an IoT Energy Monitoring System Using the Challenge-based Learning Model," in 2020 IEEE Conference on Technologies for Sustainability (SusTech), 2020, pp. $1-5$.

[69] G. Almonacid-Olleros, G. Almonacid, J. I. Fernandez-Carrasco, M. Espinilla Estevez, and J. Medina Quero, "A new architecture based on IoT and machine learning paradigms in photovoltaic systems to nowcast output energy," Sensors, vol. 20, p. 4224, 2020.

[70] D. B. Avancini, J. J. Rodrigues, R. A. Rabêlo, A. K. Das, S. Kozlov, and P. Solic, "A new IoT-based smart energy meter for smart grids," International Journal of Energy Research, 2020.

[71] G. Filios, I. Katsidimas, S. Nikoletseas, A. Souroulagkas, P. Spirakis, and I. Tsenempis, "A smart energy management power supply unit for lowpower IoT systems," in 2020 16th International Conference on Distributed Computing in Sensor Systems (DCOSS), 2020, pp. 227-235.

[72] T. Han, K. Muhammad, T. Hussain, J. Lloret, and S. W. Baik, "An Efficient Deep Learning Framework for Intelligent Energy Management in IoT Networks," IEEE Internet of Things Journal, 2020.

[73] N. K. Kumar, K. T. Sikamani, K. Cornelius, M. G. Prasana, and A. Helen, "An Efficient Dynamic Power Management of Household Energy Consumables," in 2020 6th International Conference on Advanced Computing and Communication Systems (ICACCS), 2020, pp. 11-14.

[74] C.-C. Yang, R. Pandey, T.-Y. Tu, Y.-P. Cheng, and P. C.-P. Chao, "An efficient energy harvesting circuit for batteryless IoT devices," Microsystem Technologies, vol. 26, pp. 195-207, 2020.

[75] S. Sedighiani, K. Singh, J. Huisken, R. Jordans, P. Harpe, and J. P. De Gyvez, "An Electromagnetic Energy Harvester and Power Management in 28-nm FDSOI for IoT," in 2020 9th Mediterranean Conference on Embedded Computing (MECO), 2020, pp. 1-5.

[76] K. Haseeb, I. Ud Din, A. Almogren, and N. Islam, "An Energy Efficient and Secure IoT-Based WSN Framework: An Application to Smart Agriculture," Sensors, vol. 20, p. 2081, 2020.

[77] W.-P. Kiat, K.-M. Mok, W.-K. Lee, H.-G. Goh, and R. Achar, "An energy efficient FPGA partial reconfiguration based micro-architectural technique for IoT applications," Microprocessors and Microsystems, vol. 73, p. 102966, 2020.

[78] O. Said, Z. Al-Makhadmeh, and A. Tolba, "EMS: An Energy Management Scheme for Green IoT Environments," IEEE Access, vol. 8, pp. 44983-44998, 2020.

[79] J. Arshad, M. A. Azad, M. M. Abdeltaif, and K. Salah, "An intrusion detection framework for energy constrained IoT devices," Mechanical Systems and Signal Processing, vol. 136, p. 106436, 2020.

[80] C. Lork, W.-T. Li, Y. Qin, Y. Zhou, C. Yuen, W. Tushar, et al., "An uncertainty-aware deep reinforcement learning framework for residential air conditioning energy management," Applied Energy, vol. 276, p. 115426, 2020.

[81] W.-T. Li, W. Tushar, C. Yuen, B. K. K. Ng, S. Tai, and K. T. Chew, "Energy efficiency improvement of solar water heating systems-An IoT based commissioning methodology," Energy and Buildings, vol. 224, p. 110231, 2020

[82] B. Dey, F. P. García Márquez, and S. K. Basak, "Smart energy management of residential microgrid system by a novel hybrid mgwoscacsa algorithm," Energies, vol. 13, p. 3500, 2020.

[83] S. Jagtap, A. Gandhi, R. Bochare, A. Patil, and A. Shitole, "Waste Management Improvement in Cities using IoT," in 2020 International Conference on Power Electronics \& IoT Applications in Renewable Energy and its Control (PARC), 2020, pp. 382-385.

[84] S. Aznavi, P. Fajri, R. Sabzehgar, and A. Asrari, "Optimal management of residential energy storage systems in presence of intermittencies," Journal of Building Engineering, vol. 29, p. 101149, 2020.

[85] J. Lei, C. Zhou, X. Li, A. Huang, H. Bai, Z. Yuan, et al., "Energy Management Considering Energy Storage and Demand Response for Smart Energy Hub in Internet of Things," IEEE Access, 2020.
[86] X. Yu, J. Chu, K. Yu, T. Teng, and N. Li, "Energy-Efficiency Optimization for IoT-Distributed Antenna Systems With SWIPT Over Composite Fading Channels," IEEE Internet of Things Journal, vol. 7, pp. 197-207, 2019.

[87] A. Ashiquzzaman, H. Lee, T.-W. Um, and J. Kim, "Energy-Efficient IoT Sensor Calibration With Deep Reinforcement Learning," IEEE Access, vol. 8, pp. 97045-97055, 2020

[88] V. K. Nguyen, Q. Z. Sheng, A. Mahmood, W. E. Zhang, and T. D. Vo, "Helibot-A Smart Distributed Energy Resources Platform for Futuristic Smart Grids," in 2020 20th IEEE/ACM International Symposium on Cluster, Cloud and Internet Computing (CCGRID), 2020, pp. 898-901.

[89] M. Saxena and S. Dutta, "Improved the efficiency of IoT in agriculture by introduction optimum energy harvesting in WSN," in 2020 International Conference on Innovative Trends in Information Technology (ICITIIT), 2020, pp. 1-5.

[90] M. L. Hossain, A. Abu-Siada, S. Muyeen, M. M. Hasan, and M. M. Rahman, "Industrial IoT based condition monitoring for wind energy conversion system," CSEE Journal of Power and Energy Systems, 2020.

[91] C. Mokhtara, B. Negrou, A. Bouferrouk, Y. Yao, N. Settou, and M. Ramadan, "Integrated supply-demand energy management for optimal design of off-grid hybrid renewable energy systems for residential electrification in arid climates," Energy Conversion and Management, vol. 221, p. 113192, 2020.

[92] L. Wang and D. Jiang, "Intelligent monitoring system for thermal energy consumption of buildings under the IoT technology," International Journal of Information and Communication Technology, vol. 16, pp. 53-67, 2020.

[93] G. A. Raiker, L. Umanand, S. Agrawal, A. S. Thakur, K. Ashwin, J. P. Barton, et al., "Internet of Things based Demand Side Energy Management System using Non-Intrusive Load Monitoring," in 2020 IEEE International Conference on Power Electronics, Smart Grid and Renewable Energy (PESGRE2020), 2020, pp. 1-5.

[94] H. Golpîra and S. Bahramara, "Internet-of-things-based optimal smart city energy management considering shiftable loads and energy storage," Journal of Cleaner Production, p. 121620, 2020.

[95] R. Carli, G. Cavone, S. Ben Othman, and M. Dotoli, "Iot based architecture for model predictive control of hvac systems in smart buildings," Sensors, vol. 20, p. 781, 2020.

[96] M. Ahrarinouri, M. Rastegar, and A. R. Seifi, "Multi-Agent Reinforcement Learning for Energy Management in Residential Buildings," IEEE Transactions on Industrial Informatics, 2020.

[97] Q. Lu, S. Lü, Y. Leng, and Z. Zhang, "Optimal household energy management based on smart residential energy hub considering uncertain behaviors," Energy, vol. 195, p. 117052, 2020.

[98] Q. Yu, Z. Jiang, Y. Liu, and G. Long, "Research of Power Energy Management Control Strategy with IOT in NZEB," in 2020 IEEE International Conference on Smart Internet of Things (SmartIoT), 2020, pp. 319-322. 